\title{
PROTESTANTISMO, INDIGENISMO Y MUNDO ANDINO \\ (1890-1930)
}

\section{Juan Fonseca}

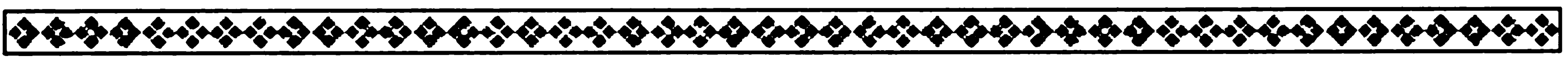

THE IINDIAN'S LAMENT

Cursed be the day, when first the white man came!

Cursed be the Spaniard, cursed his very name:

He came to us, a stranger to our soil,

To ask our help, then made of us a spoil

And took our land.

With ruthless hand

He slew our chiefs, our wives he sold to shame, And practised cruelties, in what he termed God's Name,

What mockery and everlasting shame!

We were born free, and free would be remain.

Till then to us not known was Slavery' s chain.

We loved our hills, our rulers we revered,

And no attack from anywhere we feared.

We tiled our land

With busy hand,

And were content to serve our gods in peace

As best we knew. Our fellow man to please

Was our sole aim, and Heaven to appease. 


\section{JUAN FONSECA}

Then came these foes. At first we fondly thought

That heaven had sent them here; we reverently sought

To please them well, though strange their ways appeared.

With shoutings gay a wooden cross they reared

And made us bow

As they do now

To some uplifted ornament, which they adore.

To us it is a thing which we abhor

For in its name they made us slaves the more.

O Spirit God, if such a God there be,

We know Thee not, yet grope our souls for Thee,

If Thou dost hear, O hear our humble cry,

With Thy compassionate heart draw to us nigh,

Send us Thy light,

That clear and bright,

Our star may rise, our shackles broken be,

That we may know Thy wondrous liberty -

Show us Thy grace and we will worship Thee.

George Witte

LA PRESENCIA PROTESTANTE en el PeRÚ se remonta a fines del siglo XIX, cuando el misionero metodista Francisco Penzotti abrió un salón de cultos dirigido al público peruano en el Callao, en 1888. Hasta su llegada, los diversos intentos de los misioneros protestantes habían sido aislados y efímeros. Tan pronto arribó, se dedicó a vender biblias y a adiestrar a algunos peruanos en lo mismo. Además, empezó a celebrar servicios religiosos en español en un local alquilado'. Su auditorio creció prontamente, hasta llegar a trescientas personas en los servicios dominicales. El relativo éxito de Penzotti motivó la reacción de algunos sacerdotes católicos, quienes empezaron a hostilizarlo y lograron encarcelarlo en julio de 1890. Ante el hecho,

1 Sobre Penzotti, véase su autobiografía: Francisco Penzotti, Spiritual Victories in Latin America, Nueva Cork, American Bible Society, 1916. También Juan Ritchie, "Apuntes para la historia del movimiento evangélico en el Perú", en SEL, Movimiento evangélico en la historia del Perú y en América Latina, Lima, SEL, 1985, pp. 1518; Fernando Armas, Liberales, protestantes y masones. Modernidad y tolerancia religiosa, Perú, siglo XIX, Lima, CERA Bartolomé de Las Casas - Fondo Editorial PUCP, 1993, pp. 233-286; y Samuel Escobar (Edt.), Precursores evangélicos, Lima, Presencia, 1984, pp. 119-170. 
los liberales iniciaron una vigorosa campaña para que el misionero fuera liberado. En enero de 1891, casi dos mil personas desfilaron por las calles de la ciudad en favor de la libertad religiosa $y$, específicamente, protestando por el encierro de Penzotti. Finalmente, luego de que el caso adquiriera gran notoriedad, incluso en el extranjero, el misionero fue liberado en marzo del mismo año².

\section{LAS MISIONES PROTESTANTES Y LA POBLACIÓN INDÍGENA}

Luego de ese hecho, las comunidades protestantes se asentaron progresivamente en el país, logrando formar las primeras organizaciones permanentes. En 1912, las denominaciones establecidas eran la Iglesia Metodista Episcopal, la Unión Evangélica de Sudamérica, la Misión Adventista, la Iglesia de la Santidad y el Ejército de Salvación; además de las Sociedades Bíblicas Americana y la Británica y Extranjera. Durante todo ese tiempo, aunque la práctica pública de los cultos no católicos estaba legalmente prohibida, en la práctica había una mayor laxitud, en especial en Lima. No obstante, la espada de Damocles de una sanción oficial era un importante impedimento para que las misiones protestantes pudieran desarrollarse sólidamente. La tolerancia religiosa se convirtió en el gran objetivo de los protestantes.

Años después, el hecho que originó directamente el tramo final para lograr la tolerancia religiosa fue el atropello que sufrió la misión adventista en Platería (Puno) de parte del obispo de Puno, Valentín Ampuero. Luego del incidente, Manuel Zúñiga Camacho, director de las escuelas adventistas indígenas, denunció el hecho a las autoridades de Lima. Esto provocó que el sector liberal empezara a abogar, primero por una sanción contra los hostilizadores de la misión, y luego, por un cambio de la situación legal de las comunidades religiosas no católicas. En agosto del mismo año, el senador

2 Un material básico para estudiar este acontecimiento es el proceso de Penzotti: Samuel Escobar (estudio preliminar) "Libertad religiosa en el Perú. El proceso a Francisco Penzotti (1890-1891", Época. Revista de Historia Eclesiástica, II: 3 (julio 1996), pp. 19-134. 


\section{JUAN FONSECA}

Bezada propuso la reforma del art. 4to. de la Constitución para eliminar la parte que decía: "Y no se permite el ejercicio público de otra alguna" . Contando con el apoyo del senador liberal Mariano Cornejo, los misioneros Ritchie (EUSA), Maxwell (adventista) y el pastor metodista Ruperto Algorta planificaron una estrategia para lograr su propósito. Ritchie se dedicó a la impresión de material propagandístico y Algorta a movilizar a algunos círculos obreros ${ }^{4}$. Finalmente, a pesar de la oposición clerical, la reforma fue aprobada y, dos años después, el 11 de noviembre de 1915, la ley fue promulgada.

Dadas las condiciones para un trabajo más libre, las misiones protestantes empezaron a experimentar un crecimiento progresivo en las dos primeras décadas del siglo XX. No solamente aumentó el número de denominaciones establecidas, sino que también la red de congregaciones se extendió en varios departamentos del país y el número de adherentes tuvo un incremento significativo. Además, la variedad de actividades y campos de acción de los misioneros y pastores se amplió notablemente. Como parte de la estrategia misionera, se fundaron colegios, clínicas, enfermerías, haciendas, y se relacionaron con diversas agrupaciones y movimientos sociales e ideológicos. Dentro de todo esto, el trabajo entre y hacia los indígenas se constituyó en un objetivo privilegiado dentro de la cruzada protestante para "regenerar la nación"5.

En el caso de los indígenas, un espacio privilegiado para el acercamiento a ellos fue el Sur Andino. En Cusco, en 1908, la UESA adquirió la hacienda "Urco", en la provincia de Calca, donde vivía un determinado número de familias indígenas que pagaban el uso de la tierra con su fuerza laboral. El objetivo de la hacienda era influir en el estilo de vida de los indígenas, para lo cual se estableció

3 Herbert Money, La reforma del Art. 4to. de la Constitución del Perú: 1915, Lima, CONEP, 1965, p. 17.

4 "La libertad de cultos. Apuntes para la historia", El Mensajero (Órgano oficial de la Iglesia Metodista Episcopal del Perú), Lima, IL/13 (diciembre 1915), p. 9.

5 Sobre el movimiento protestante en general, ver nuestra tesis Entre el conflicto y la consolidación. Protestantismo y modernización en el Perú (1915-1930), Lima, Pontificia Universidad Católica del Perú, 2000. Además, es fundamental la obra de Juan Kessler, Historia de la evangelización en el Perú, Lima, Puma, 1993. 
una pequeña escuela, pues se tenía la esperanza de que, a través de los niños, los indígenas adultos cambiasen sus costumbres. Además, se introdujeron modernos sistemas de cultivo y se prohibieron prácticas tradicionales andinas tales como el consumo de coca y las fiestas patronales. No obstante, cuando en 1922 el misionero Charles Inwood la visitó, informó que no había indígenas convertidos ${ }^{6}$.

Sin embargo, en otros lugares hubo mejores resultados en el proceso de conversión de los indígenas. Así, la UESA logró establecer congregaciones en algunos pueblos indígenas de Cusco (Sicuani, Huantura, Checacupe, Pitumarca) y Puno (Ayaviri), pero recién a firiales de la década7. En la sierra central, la ACM estableció congregaciones entre las comunidades indígenas de las provincias de Dos de Mayo, Ambo y Pachitea (Huánuco), los pentecostales en Huancayo, e incluso los metodistas informaron que tenían miembros indígenas en algunas de sus congregaciones ${ }^{8}$. Finalmente, habría que contar con las bases misioneras de la selva, como la de la ACM entre los campas de Cahuapanas (Pachitea - Huánuco) y la misión nazarena entre los aguarunas de Pomará (Amazonas) ${ }^{9}$.

6 Posteriormente, Juan Ritchie cuestionó la efectividad evangelizadora de la hacienda. Ésta estaba registrada con el nombre de "Sociedad Anónima Inglesa". "A Traveller's Notes. Mr. Strachan's Tour in Chile, Peru and Bolivia", South America, VI: 10 (febrero 1918), pp. 95; Peter Savage, The Ministry in the Iglesia Evangelica Peruana (mono.), Faculty of the School of World Mission Fuller Theological Seminary, 1967, p. 53; Kenneth Grubb, The West Coast Republics in South America, Londres, World Dominion Press, 1939 , p. 87.

7 Len Herniman, "Sicuani - A Quechua Indian District and Neighbourhood", Neglected Continent, 6: 11 (junio 1925), pp. 374-376; Mr. And Mrs. Tyson, "Joy Bells at Huantura", Neglected Continent, 8: 3 (junio 1929), pp. 44-46.

8 En 1930, los delegados de la congregación de Nunaraico (Dos de Mayo) a la convención departamental de la $\mathrm{ACM}$ en Huánuco fueron los jóvenes indígenas Apolonio Ayra y Valentín Cajaleón. "Notas", Renacimiento, 224 (mayo 1930), p. 78; W.F. Montaño, "Campaña de evangelización en el Perú central", Renacimiento, 212 (mayo 1929), pp. 75-76; C. W. Brewster, "The Central District", Inca Land, IV: 4 (agosto 1928), pp. 50-55.

9 Amy Hinshaw, The Trail of the Aguaruna (A Life Story of Esther Carson Winans), Kansas City, Mo., Nazarene Publishing House, s.f.,; George Mc Intosh (Edt.), The Money Memoirs. New Zealand and Peru. Dr. Herbert Money, Tayport, 1989, Vol. II, p. 58; Eloy González, Presencia misionera en el norte del Perú, Chiclayo, Vol. II, p. 52. 


\section{JUAN FONSECA}

No obstante, estos logros no se comparan con lo que los adventistas alcanzaron en el Altiplano peruano. Luego de los incidentes de 1913, la obra adventista, dirigida por los misioneros Ferdinand y Ana Stahl y el indígena Manuel Zúñiga Camacho, experimentó un periodo de notable auge gracias a su modelo de formar "ciudadanos productivos"10. Con el tiempo, el adventismo se convirtió en una especie de religión social en el Altiplano, pues muchos indígenas se identificaban como tales, a pesar de no pertenecer formalmente a los registros de los Iglesia. Dicha identificación partía del rol social que jugaba la Iglesia a favor de los indígenas. La combinación de la predicación con la obra educativa y médica de los misioneros abrió las puertas para que las congregaciones adventistas se multiplicaran por la zona ${ }^{11}$.

\section{PROTESTANTISMO E INDIGENISMO}

A inicios del siglo XX, la sociedad peruana se vio transformada por una serie de nuevas presencias que obligaron a nuevos debates sobre aspectos hasta ese tiempo postergados. Así, aunque la mayoritaria composición indígena de la población peruana ya había sido objeto del debate entre los intelectuales del siglo XIX, en las primeras décadas del XX alcanzará una inusitada importancia en la discusión intelectual y política. Esto principalmente porque el eje de las reflexiones giró hacia la búsqueda de la afirmación del Perú como entidad nacional. Ese fue el caso de la Generación del 900, para cuyos representantes la recuperación de la historia debía incorporar

10 Sobre el adventismo en el Perú, ver Charles Teel, "Las raíces radicales de la Iglesia adventista peruana", Allpanchis 33 (1989), 209-248. También se pueden ver relatos de los propios protagonistas, como Ferdinand Stahl, In the Land of the Incas, Mountain View, CA, Pacific Press, 1920; y Pedro Kalbermatter, 20 años como misionero entre los indios del Perú, Puno, s/f. También Ted Lewellen, "The Adventist Elite", en Peasants in Transition: The Changing Economy of the Peruvian Aymara: A General Systems Approach, Boulder, CO, Westview, 1978, 109-139.

11 Stahl resume así su modelo misionológico: "Preaching the gospel, unless it carries with it sympathetic help for the body as well, cannot be expected to accomplish much among this needy people". Citado en Gregory Cushman, The Gospel of Growth and Organization: Interpreting the Arrival of the Latin America and Caribbean Seventhday Adventist Church (inédito), p. 12. 
al elemento indígena, no solamente en su faceta prehispánica, dentro de la imaginada evolución de la nación peruana. Aunque intelectuales positivistas como Javier Prado habían trabajado sobre la historia incaica, éstos tendían a ver al elemento indígena más como un penoso lastre que la nación peruana (es decir, la elite) debía soportar. Algunos propusieron remediar ello mediante la inmigración y el "mejoramiento racial", con poco éxito. La Generación del 900 se planteó el problema en términos diferentes. El elemento indígena ya no era un lastre, sino una realidad que debía ser incorporada. Así, la observación del joven Riva-Agüero, que el Perú se salvaba con el indio o se hundía con él, refleja bastante bien el ánimo de las corrientes de ideas de estos primeros periodos.

Por otra parte, los protestantes, quienes consolidarían su presencia en las primeras décadas del siglo XX, también tuvieron una posición en este debate. A pesar de la modesta proporción de indígenas entre la naciente comunidad protestante, las diversas misiones plantearon e iniciaron proyectos para influir entre los indígenas en el país. No obstante, al acercarse a ese importante sector de la población, era imposible desconocer el debate de la intelectualidad peruana sobre el elemento indígena. El naciente movimiento indigenista influyó notablemente en la configuración de las percepciones sobre los indígenas y en ello los misioneros no fueron ajenos. Además, estos últimos llegaron con ideas propias sobre los indígenas, que se combinaron con las que aquí encontraron. Así, la labor protestante a favor de los indígenas y sus percepciones sobre ellos fue el resultado de una combinación de las ideas traídas por los misioneros y de los planteamientos del movimiento indigenista.

$\mathrm{El}$ indigenismo fue fundamentalmente un movimiento intelectual que luego derivó en posiciones políticas concretas. Aunque tuvo precursores desde mediados del siglo XIX, el movimiento indigenista tuvo como principal iniciadora a Clorinda Matto de Turner, quien, bajo la influencia de González Prada, publicó novelas y diversos escritos en los que mostraba la terrible situación en la que vivían los indígenas de su tiempo. No obstante, con el ingreso de Piérola al poder, tuvo que salir del país y continuar su obra en Argentina. Su prédica era fuertemente anticlerical, positivista y se expresaba políticamente a favor de la industrialización del país, por 


\section{JUAN FONSECA}

lo que sus críticas se dirigían principalmente a los latifundistas y a la oligarquía exportadora. Posteriormente, la política indigenista de Leguía reflejó en gran medida los planteamientos de Matto de Turner. En lo religioso, el que estuviera casada con protestante inglés y tradujera partes de la Biblia al quechua sugieren que su cristianismo estuvo más cerca del protestantismo que del catolicismo que tanto criticó" ${ }^{12}$. No obstante, el indigenismo fue "fundamentalmente un fenómeno literario urbano que expresa los puntos de vista que tienen los ciudadanos al respecto" ${ }^{13}$; su función fue mostrar al público urbano una realidad casi desconocida $y$, por consiguiente, incomprendida. Por ello, las posturas fueron muy diversas. Pero, a diferencia de otras corrientes, que también habían incluido a los indígenas en sus escritos como un elemento ornamental y lejano, los indigenistas propiciaron la formación de posturas y programas políticos respecto al indígena.

De esta forma, en las primeras décadas del siglo XX, algunos intelectuales indigenistas formaron la Asociación Pro-Indígena, grupo destinado a promover una legislación que garantizara a los indígenas el acceso al mercado libre de trabajo y se eliminaran los abusos contra ellos por parte de las autoridades. Pedro Zulen, Dora Mayer y Joaquín Capelo fueron los principales dirigentes de este grupo. Hasta su disolución en 1917, hizo una importante labor de presión al Gobierno y de defensa de los indígenas. Después, durante el Oncenio, Leguía promovió una activa política indigenista. En ello, como ya dijimos, rescató los aportes de Clorinda Matto de Turner, con quien compartía las mismas ideas respecto a la importancia de la industrialización en el Perú, con la apertura a los capitales extranjeros, así como su admiración por lo anglosajón ${ }^{14}$. Sin embargo, los

12 Según Vásquez, ella tradujo en Buenos Aires los evangelios de san Marcos y san Juan y los Hechos de los Apóstoles, con la colaboración de misioneros protestantes. Adolfo Vásquez, Datos históricos de la Iglesia Metodista Episcopal (inédito), Lima, 1937. p. 18.

13 Efraín Kristal, Una visión urbana de los Andes. Génesis y desarrollo del indigenismo en el Perú, 1848-1930, Lima, Instituto de Apoyo Agrario, 1991, p. 203. En esta parte sigo básicamente sus planteamientos.

14 Kristal señala que los literatos que trataban e incorporaron el elemento indígena en sus obras estuvieron muy ligados a sus posiciones políticas. Él distingue 
críticos al régimen, entre ellos muchos de los indigenistas, advirtieron que las medidas de Leguía eran demagógicas y que hacían realmente poco a favor de los indígenas. El indígena fue convertido en una "prenda retórica" para muchos políticos e intelectuales. Así, hacia 1930, se culminó todo un periodo del debate indigenista en el Perú. A partir de allí, los nuevos grupos socialistas y populistas plantearon nuevas percepciones sobre el indígena, creando una nueva etapa de literatura indigenista en el país.

La relación entre los misioneros protestantes y los indigenistas fue bastante positiva. Los primeros, desde un inicio, apoyaron la Asociación Pro-Indígena, informando de sus actividades y promoviendo la participación de los miembros de sus congregaciones en ella ${ }^{15}$. También apoyaron activamente algunas de sus iniciativas legislativas, en especial las que favorecían la reducción de la influencia clerical entre los indígenas. Ese fue el caso de la ley sobre el cargo de mayordomo en las fiestas religiosas indígenas, promovida por la Asociación a raíz de algunas denuncias hechas por indígenas que habían sido forzados a aceptar dicha responsabilidad en contra de su voluntad. A través de dicha ley, se prohibió a las autoridades civiles y religiosas obligar a los indígenas a aceptar ese cargo. Éste era un problema especialmente difícil para los protestantes indígenas, quienes se veían comprometidos a participar en actividades

tres posturas: la de los que favorecían el antiguo sistema de los terratenientes, la de los "exportadores" y la de los "industrializadores". Las dos últimas, básicamente, fueron las que empezaron a "mostrar" la realidad de los indígenas, cuestionando los abusos a los que el latifundismo los sometía. En el programa político del civilismo predominó la tendencia de los "exportadores", que aunque cuestionaban los abusos, abogaban por una incorporación tutelada del indígena al sistema político. Matto de Turner y González Prada, en cambio, propugnaron la tendencia "industrializadora", que promovía la plena incorporación del indígena al mercado libre de trabajo, lo que, paralelamente, destruía la comunidad, dejando al indígena huérfano del apoyo comunal. Ibid., pp. 15-36. También ver Wilfredo Kapsoli, El pensamiento de la Asociación Pro-Indígena, Lima, Debates Rurales, 1980.

15 "Llamamos la atención de los que simpatizan en la causa a la valiosa colección de leyes y decretos que la Asociación Pro-Indígena acaba de publicar en forma de folleto". "Pro-Indígena", El Heraldo. Periódico religioso mensual, Lima, 43 (abril 1915), p. 69. También se informaron reportes de sus reuniones y actividades. "Pro- Indígena", El Heraldo, 2 (noviembre 1911), pp. 6-7; "Lo que pasa", El Mensajero. Órgano oficial de la Iglesia Metodista Episcopal del Perú, Lima, 6 (mayo 1915), p. 10. 


\section{JUAN FONSECA}

prohibidas por su nueva religión. Por ello, los misioneros, duros críticos de esas fiestas, apoyaron decididamente esa iniciativa de la Asociación ${ }^{16}$.

Asimismo, los misioneros abrieron sus publicaciones para que connotados indigenistas como Dora Mayer y José Antonio Encinas expresaran sus ideas, las que eran acogidas favorablemente. Ellos, por su parte, escribieron elogiosos artículos sobre la labor de los protestantes en beneficio de los indígenas. Así, José Antonio Encinas señalaba que los misioneros protestantes trataban "con verdadero criterio sociológico" el "problema" indígena, a diferencia del sistema de "explotación" impuesto por los sacerdotes católicos. Los pastores protestantes inculcaban a los indígenas hábitos de higiene, sobriedad y laboriosidad a través de la educación. Sin embargo, abordaban el factor religioso en los siguientes términos:

"El problema de la regeneración de la raza no puede resolverse sino dentro del criterio religioso, mientras la conciencia del indio no adquiera la fuerza necesaria para guiarse sin este control. Sólo si hay que comenzar por apartarlo de toda supertición (sic). Por independizarlo de todo aquello que las prácticas religiosas absurdas han dejado como sedimento en su conciencia. Felizmente, esta labor la realizan admirablemente los diferentes grupos de protestantes que viven en el Perú. (...) Yo hago un llamado a la juventud de mi patria para apoyar esta obra de los protestantes. Ellos nos han de devolver a los indios convertidos en ciudadanos útiles para el país. No averigüemos si el indio ha de resultar protestante ó nó (sic), averigüemos si ha dejado sus vicios, su incuria, si ya sabe el nombre del suelo que pisa, las leyes que lo cobijan, los derechos que tiene" 17 .

16 "El cargo de mayordomo para las fiestas religiosas", El Heraldo, 37 (octubre 1914), pp. 6-7; "Leyes y ordenanzas que afectan a las instituciones libres y los disidentes de la Iglesia romana", Renacimiento. Revista evangélica interdenominacional, Lima, 139 (abril 1923), pp. 57-58.

17 J.A. Encinas, "El valor del protestantismo en el Perú", El Mensajero, 3 (febrero 1915), pp. 5-6. Él mismo escribió otro artículo tres años después: "La labor moralizadora de los evangelistas", La Prensa, Lima (5-enero-1918). 
Así, en su perspectiva, el protestantismo es valioso para los indígenas en tanto influencia cultural y "civilizadora". Pero, como alternativa religiosa, era sólo un mal menor y, en todo caso, sólo útil temporalmente para eliminar las "supersticiones" de los indígenas y prepararlos para una auténtica liberación en la que la religión ya no sea necesaria. Teodomiro Gutiérrez, el conocido Rumi Maqui, desarrolló planteamientos similares en otro artículo. Allí señalaba que los indígenas convertidos al protestantismo:

"Conocen y practican las reglas de la higiene, visten á la usanza de los pueblos de la costa, no beben alcohol ni licores espirituosos, no mascan coca, han aprendido a tomar una sólida alimentación, concurren con exactitud á sus prácticas religiosas, se dedican al trabajo con empeño decidido y saben que se deben por entero al servicio de la República, como lo comprobaron concurriendo en masa al llamamiento que hizo el Estado Mayor de la Región Militar en 1913 para el período de instrucción, caso único en la historia de la República, tratándose de indígenas"18.

Su entusiasmo por la labor de los protestantes lo lleva a afirmar, al final del artículo, que la solución para los problemas de los indígenas era colocar un pastor protestante en cada provincia del país. Ello se explica porque ese año Gutiérrez se había convertido al protestantismo, incorporándose a la IME como miembro pleno. Con la emoción propia del nuevo converso, explicaba su adhesión al protestantismo por los contrastes que observó entre los sacerdotes católicos y los pastores protestantes en su relación con los indígenas. Eso "no ha hecho sino llevar mi ánimo el profundo convencimiento de la bondad, moralidad y pureza de la enseñanza de la Iglesia Metodista de la verdadera doctrina de Jesucristo conforme al texto del gran libro de las más puras y sabias enseñanzas: la $\mathrm{Bi}$ -

18 Teodomiro Gutiérrez, "La influencia de los pastores evangelistas en la educación moral de los indígenas”, El Mensajero, 4 (marzo 1915), p. 10. Cf. Dora Mayer, "La química social", El Deber Pro-Indígena, Lima, 13 (octubre 1913), p. 105. 


\section{JUAN FONSECA}

blia" ${ }^{19}$. Aunque fue finalmente el contacto con el texto bíblico el que motivó su conversión, la motivación inicial fue más bien ética: el darse cuenta de que el protestantismo podía ofrecer un mejor estilo de vida a los indígenas a quienes defendía. No obstante, su punto de referencia, al igual que el de Encinas, era la notable obra realizada por los adventistas entre los indígenas de Chucuito (Puno), lugar donde fue inspector. Pero los adventistas no eran considerados por los protestantes como parte de la misma familia; sin embargo, en el contexto de la lucha por lograr la legitimación legal en el país, los misioneros protestantes no se preocuparon por aclarar esa distinción a los confundidos indigenistas.

Finalmente, durante el Oncenio, los protestantes mantuvieron una actitud cautelosa frente al Patronato de la Raza Indígena creado por Leguía. Aunque estaban de acuerdo con sus objetivos generales, sospecharon que era un mecanismo para reforzar el control del clero católico y eliminar toda influencia protestante en los pueblos indígenas. El art. 4to. del proyecto de reglamentación fue especialmente criticado porque iba "a acabar de quitarle al indígena cualquier vestigio de iniciativa de mejoramiento propio y de libertad personal"20. Las suspicacias de los misioneros parecieron confirmarse cuando, meses después, uno de ellos, Thomas Payne, administrador de la hacienda "Urco" (Calca- Cusco), de propiedad de la UESA, quien era además un "conocido defensor de los indígenas", fue impedido de conformar la junta provincial del Patronato en Calca por ser protestante ${ }^{21}$. El hecho de que el obispo del Cusco

19 "Iglesia meiodista de Lima", El Mensajero, 2 (enero 1915), p.14. Alli se reportó que el 27 de diciembre de 1914, "fue recibido como miembro de la Iglesia Metodista Episcopal el sargento mayor del ejército del Perú, señor Teodomiro Gutiérrez, persona distinguida, quien ha sido juez militar en Cajamarca, subprefecto en Huancayo, comisionado del gobierno en el departamento de Puno".

20 "Editoriales", Renacimiento, 132 (septiembre 1922), p. 130. El mencionado artículo manifestaba lo siguiente: "Que el gobierno organice y perciba la cuota que hoy día se han impuesto a los indios y pagan voluntariamente, y con sus productos sostengan los tribunos, curas, médicos y demás personas que deben prestar servicios gratuitos a los indios". Con ello los indígenas quedaban obligatoriamente sujetos a la autoridad del clero católico.

21 Payne había sido propuesto por el Dr. Lorena, un "notable" de la ciudad. El vicepresidente del Patronato en Cusco pidió a los directivos que se consultara a 
fuera el presidente de la Junta Departamental obviamente influyó en esa decisión. Asimismo, algunas otras agrupaciones indigenistas, como el Comité Pro-Derechos Indígenas Tawantinsuyo, no tenían la confianza de los protestantes:

"Últimamente, ha tomado (el Estado) la oportuna medida de suprimir el funcionamiento del Comité Pro Derechos Indígenas Tawantinsuyo, que surgió al principio con un buen programa de acción e inspirado con sinceridad, para caer en manos de leguleyos y tinterillos inescrupulosos, convirtiéndose en seria amenaza a la tranquilidad nacional" 22 .

A pesar de ello, es claro que el apoyo indigenista a la obra protestante fue eminentemente cultural. La educación y la ética provista por los agentes religiosos protestantes eran convenientes para promover entre los indígenas una progresiva separación de las costumbres que los "degeneraban" y prepararlos para la vida moderna. Las opciones religiosas que tomaran los indígenas no eran demasiado importantes, si es que ellas promovían su incorporación a la "civilización". En el aspecto político, se buscaba que el indígena sea obediente a las leyes y se identifique con su patria. En el aspecto económico, el objetivo era formar en él hábitos que lo acostumbraran al trabajo, el ahorro y la disciplina; es decir, costumbres que lo capacitaran para incorporarse a un sistema de trabajo libre y alejarse del cuestionado sistema de servidumbre propio del latifundismo tradicional. Para ambos fines, el protestantismo también podía contribuir.

Lima si es que los pastores protestantes podían ingresar a las juntas provinciales. No obstante, el obispo, además presidente del Patronato, se opuso firmemente a ello, publicando una carta en El Diario (4-diciembre 1922), periódico cusqueño, acusando al vicepresidente de "adorador" y "panegirista" de los protestantes. Finalmente, el Dr. Lorena retiró su propuesta, pues "había creído de buena fe que los pastores protestantes eran elementos de progreso". El Comercio de Cusco publicó detalles del incidente (2, 6, 7 diciembre 1922). "Editorial", Renacimiento, 136 (10-enero 1923), p. 3.

22 "Tópicos del mes", Renacimiento, 192 (septiembre 1927), p. 135. 
JUAN FONSECA

\section{UNA MIRADA AL MUNDO ANDINO DESDE LOS PROTESTANTES}

Para la formación de sus ideas sobre la población indígena, los misioneros protestantes llegaron con ideas propias de sus respectivos contextos, las cuales se combinaron con la influencia indigenista para elaborar una especie de "indigenismo protestante". Como parte de la civilización anglosajona, los misioneros tenían una visión compasiva de los indígenas, cuya cultura era considerada inferior. Asimismo, compartían con la intelectualidad de la época rasgos positivistas al explicar muchos de sus problemas con argumentos raciales $^{23}$. Finalmente, eran ácidamente críticos a los hábitos ancestrales andinos como el consumo de la coca, las creencias religiosas y las festividades. En ello tenían una perspectiva coincidente con la de la mayoría de los intelectuales, incluso con los indigenistas. Pero estos últimos influyeron en los misioneros en su interés por conocer de cerca la realidad indígena y, principalmente, en las acciones que tomaron a su favor. En su acercamiento a la realidad indígena, los misioneros emitieron evaluaciones como estas:

"Todos los indios me parecen flacos y hambrientos, sin embargo, aún es inusual un verdadero estado de inanición. Pero vivir en la suciedad y la podredumbre, la ignorancia y la pobreza, la superstición y el temor, en una vida puramente animal, no es lo que Dios desea para los seres humanos (...). Han sido explotados por la codicia y descuidados por la Igle-

23 Aunque reconocían la capacidad de los indígenas para diversas labores, los consideraban aún inferiores a la raza blanca: "These achievements (destreza agrícola y artesanal) indicate some degree of intellectual capacity. Judging from his general appearance, his physiognomy, his behavior and work, some have considered the Quechua Indian far above the Australian black in the scale of intelligent beings, perhaps above the Kaffir and Hottentot, and the North American Indian, but below the Maori of New Zealand". Committee on Cooperation in Latin America (CCLA) (Edt.), Christian Work in South America. Official Report of the Congress on Christian Work in South America at Montevideo, Uruguay, April 1925, Nueva York, Fleming H. Revell Company, 1925, t. I, p. 170. 
PROTESTANTISMO, INDIGENISMO Y MUNDO ANDINO (1890-1930)

sia. Continuarán viviendo en niveles tan bajos hasta que reciban educación y justicia" 24 .

"(Los indígenas) son trabajadores, sufridos, delatando en las facciones de su rostro su ascendencia netamente incaica, callados y recelosos a causa de la opresión y explotación inícua (sic) de que han sido objeto por más de cuatrocientos años, víctimas del vicio tan común de la coca y las bebidas, y de la avidez insaciable de riquezas del clérigo que los visita dos o tres veces al año para'llevarse los pequeños ahorros que han podido juntar" 25 .

Ambas percepciones, de un metodista norteamericano y de un evangélico español, son bastante similares a las de la mayoría de los intelectuales. No obstante, en el análisis de la problemática social, la influencia de las ideas indigenistas es más ostensible, pues señalan como causa de su atraso la falta de educación, al alcoholismo y a la explotación de las autoridades. La crítica á lo que González Prada llamó la "trinidad embrutecedora" de los indígenas ${ }^{26}$ se manifiesta también en los escritos protestantes, aunque enfatizando la responsabilidad de los sacerdotes católicos.

Las críticas a los latifundistas son dirigidas principalmente al sistema, mientras que se nota mucha cautela al criticar a las autoridades políticas. En el congreso sobre la Obra Cristiana en Montevideo (1925), los misioneros del Perú resumieron su estrategia de acer-

24 "All Indians look thin and hungry to me, yet real starvation, is inusual. But to live in dirt and filth, ignorance and poverty, superstition and fear, a purely animal life, is not what God expected of human beings. (...) They have been exploited by greed and neglected by the church. They will continue to live on the lower level until they are given the gospel education and justice". Marvin Rader, "Evangelizing Beyond the High Sierras", Inca Land. Official Publication of the Methodist Episcopal Church in Peru, II: 2 (marzo-abril 1926), p. 20.

25 Manuel Garrido Aldama, "En el Sur del Perú - La Unión Evangélica de Sur-América", Renacimiento, 196 (enero 1928), p. 6.

26 Ya, en 1912, John Jarrett criticaba la situación de opresión indígena por los curas, las autoridades locales y los terratenientes. John Jarrett, Fifteen Years in Peru. The Story of a Struggle on Behalf of Religious Liberty. Londres, Regions Beyond Missionary Union, 1912, pp. 17-24. 


\section{JUAN FONSECA}

camiento a los indígenas en tres aspectos: a) industrial y económico, que les permita aprender nuevas técnicas agrícolas y actividades industriales; b) educacional y médico, creando escuelas y centros médicos para ellos; y c) problemas sociales, básicamente combatiendo el alcoholismo, el uso de la coca, el desaseo y el concubinato ${ }^{27}$. Era una perspectiva limitada en sus alcances sociales.

En su acercamiento a la realidad andina, los protestantes también desarrollaron algunas concepciones sobre el pasado andino. Para ello, utilizaron principalmente la visión del historiador inglés Clement Markham. La percepción de un pasado incaico brillante se confronta con la sombría existencia de los indígenas durante el virreinato. Los obrajes, la mita minera, el sistema de tributación y la represión de la revuelta tupacamarista fueron aspectos especialmente resaltados por algunos misioneros, empeñados en mostrar la "bárbara" situación en la cayeron los indígenas bajo el dominio español; una "raza oprimida", según la opinión del misionero adventista F.A. Stahl28.

La percepción del estado religioso de los indígenas fue el asunto que más desarrollaron los misioneros. La opinión más general era que "las religiones de las tribus americanas son una mezcla de brujerías y supersticiones" 29 . Esa idea era un axioma para interpretar las prácticas religiosas de los indígenas peruanos en las descripciones que hacían. Aunque imaginaban que la religión del Tahuantinsuyo tenía ciertos caracteres apreciables, no podían comprender que, luego de varios siglos de evangelización, se combinaran ceremonias y festividades católicas con devociones andinas que culminaban con francachelas colectivas en las que el alcohol, el

27 CCLA (Edt.), Christian Work in South America. Official Report of the Congress on Christian Work in South America at Montevideo, Uruguay, April 1925, Nueva York, Fleming H. Revell Company, 1925, t. I, pp. 175-177.

28 Ver Thomas Wood, "The Land of the Incas", en Varios, Protestant Missions in South America, Nueva York, Student Volunteer Movement for Foreign Missions, 1900, pp. 141-160; Harry Guinness, "The Children of the Sun. The tragic Story of the Inca Indians of Peru", en Regions Beyond, 27:8 (agosto 1906) pp. 195-205.

29 "Algunas creencias y supersticiones de algunas tribus americanas", Renacimiento, 203 (agosto 1928), p. 124. También ver "Creencias y supersticiones de los indios jaujinos", Renacimiento, 198 (marzo 1928), p. 39. 
juego y la promiscuidad no podían faltar. Desde la perspectiva protestante, con una ética puritana y frugal, dichas prácticas eran totalmente deleznables e incompatibles con el cristianismo.

Además de ello, las propias devociones católicas les parecían idolátricas. Para un misionero metodista, "el materialismo es el término que describe la religión del Perú" 30 . Es la misma postura de Mariátegui en los Siete ensayos cuando señala que el catolicismo colonial fue eminentemente ritual, mientras que el protestantismo era una religión práctica y fundamentalmente ética. Para una sociedad moderna, entonces, el protestantismo era más adecuado que el catolicismo ${ }^{31}$. Así, los protestantes sostenían que la mejor alternativa religiosa para mejorar la situación de los indígenas y, de una manera general, contribuir al desarrollo del país, era la predicación del protestantismo en medio de un sistema de libertad religiosa. Un misionero lo expresó así:

(El catolicismo) no es la religión que conviene para los indígenas, minando la salud y virilidad de la raza de este mundo, y condenándoles en el otro, a pesar de todo "misticismo". (...) Sabemos que razas muy inferiores a nuestros indios han sido convertidos, por la predicación del evangelio puro, a una vida de utilidad, inteligencia y de santidad práctica. (Con la separación de la Iglesia del estado), millares de peruanos se sentirían mas libres para "escoger su religión" y no dudamos que el protestantismo, o el evangelio puro y no mercenario, tendría su día 32 .

30 "Crosses", Inca Land, II: 4 (julio-agosto 1926), p. 50. En ese artículo, el autor irónicamente señala que las verdaderas "cruces" que los indígenas tienen son la idolatría, la ignorancia ("intellectual slavery"), el alcoholismo y la degradación de la mujer.

31 José Carlos Mariátegui, Siete ensayos de interpretación de la realidad peruana, Santiago, Universitaria, 1955, pp. 169-185.

32 T. W. Smith, "Manifestaciones de incultura", El Cristiano, 80 (mayo 1918), pp. 68-69. Lo mismo decía el metodista peruano Ruperto Algorta: "Convencido de que esta idolatría no desaparecerá hasta que el evangelio de Cristo sea proclamado en esta ciudad, y los mercaderes sean arrojados del templo". "La fiesta del Señor de Luren de Ica", El Mensajero, 12 (noviembre 1915), p. 11. 


\section{JUAN FONSECA}

Con estas ideas, los misioneros elaboraron los lineamientos centrales de su labor con los indígenas. Por un lado, algunos afirmaban con radicalidad los derechos de los indígenas, mientras que otros lo hacían con mucha cautela. Así, uno decía: "Mientras el indio se arrastre a los pies del gamonal, víctima de los vicios y de la tiranía clerical (...), no podemos jactarnos de la verdadera libertad"33. Cuando ocurrió una sublevación indígena en Puno, cierto sector de la prensa involucró a los adventistas como responsables de promover la sedición. Ello motivó el rápido deslinde de los protestantes, quienes aclararon sus diferencias con ellos y afirmaron que más bien deberían establecerse más misioneros, pues "su presencia serviría para influir en los indígenas contra los excesos; su enseñanza encauzaría el bullicio intelectual del cerebro del indio por surcos de mejoramiento intelectual y espiritual" 34 .

\section{EL INDIGENISMO PROTESTANTE: LAS ACCIONES}

A pesar de estas ambigüedades, las misiones protestantes, desde sus inicios, estuvieron muy interesadas en hacer una labor con los indígenas. Los colportores de las sociedades biblicas dirigieron una buena proporción de sus esfuerzos a ellos, porque "ninguna clase de personas necesita más el Evangelio que los indios quechuas" 35 . La IME, por su parte, formó en 1914 una Comisión de Asuntos Indígenas "para buscar informaciones sobre la condición de la raza indígena y los medios de mejorar la misma" ${ }^{36}$; mientras que la Sociedad Misionera Nacional, formada por metodistas peruanos, anun-

33 B.V.S., “¿Somos verdaderamente libres?”, El Cristiano, 106 (julio 1920), p. 105.

34 "Tópicos del mes", Renacimiento, 122 (noviembre 1921), p. 162. Posteriormente, algunas revueltas indígenas fueron acusadas de "comunistas". "Tópicos del mes", Renacimiento, 192 (octubre 1927), p. 135.

35 "No class of people needs the Gospel more than the Quechua Indian". D.C. Brackenridge, "And the Word of God increased", Inca Land, II: 6 (noviembrediciembre 1926), p. 89.

36 "Diario de la conferencia", Actas de la Sexta Reunión de la Conferencia Misionera Andina del Norte de la Iglesia Metodista Episcopal, Lima (12-16 noviembre 1914), p. 11. 
ció que su objetivo central era "difundir en el Perú, y de un modo especial entre la raza indígena del país, el conocimiento de las doctrinas de las Sagradas Escrituras, como lo declaran los Artículos de Fe de la Iglesia Metodista Episcopal" 37 . No obstante, la UESA fue la que tomó con más seriedad el asunto indígena, pues sus misioneros pensaban que:

"Es imposible que el movimiento evangélico tome cuerpo en el país sin obrar un cambio radical en la manera de mirar y tratar al indio. Para él, el movimiento evangélico, aunque no lo comprenda ni crea, significa emancipación. El intento de defenderlo pasará a uno de educarlo, y esto será como explotar una mina bajo las trincheras del sistema actual"38.

Este planteamiento fue expresado concretamente con una serie de obras realizadas a favor de los indígenas, especialmente en el sur del país. La más importante de ellas fue la obra de la hacienda Urco en Calca, adquirida en 1908 e inscrita como "The Inca Schools Society - Sociedad Pro-Indígena de Agricultura e Instrucción”. Uno de sus misioneros resumió así sus labores:

"Allí se introducen nuevas semillas, animales de crianza, e implementos modernos. Se practican los mejores métodos agrícolas, instruyendo en estos métodos científicos a los indígenas. Se combaten las enfermedades de las plantas y de los ganados, no sólo dentro, sino también fuera de la hacienda. Se educan a los niños indígenas que residen en la hacienda y se protejen (sic) a los indígenas de toda la comarca. Se cuida un buen número de huérfanos y niños abandonados, y se cuidan y curan a muchos enfermos, algunos de éstos traídos alli desde distancias considerables" 39 .

37 "Sociedad Misionera Nacional", El Mensajero, 18 (junio 1916), p. 8.

38 "Editorial", El Heraldo, 45 (junio 1915), p. 86.

39 "Nuestro grabado", El Cristiano, 86 (noviembre 1918), p. 165. 
JUAN FONSECA

En el aspecto agrícola y ganadero, la hacienda obtuvo un pronto reconocimiento de los hacendados vecinos, algunos de los cuales cedieron parte de sus terrenos para que la misión abriera granjas y escuelas para los indígenas. Además, en 1919, la hacienda recibió una condecoración al sobresalir con sus productos en una exhibición agrícola en Cusco. Un diario cusqueño reportó así el hecho:

"Las condiciones privilegiadas del suelo y el clima favorecen excepcionalmente al crecimiento de la agricultura. De esto, tenemos un ejemplo práctico en la hacienda de Urco, propiedad de un entusiasta grupo de extranjeros. Sus magníficos productos exhibidos en su exposición han causado sorpresa general debido a su calidad y tamaño" ${ }^{40}$.

No solamente se procuró formar técnicamente a los indígenas, sino también se buscó inculcar en ellos hábitos tales como la abstinencia alcohólica, la puntualidad y la disciplina laboral. Además, consecuentes con sus objetivos religiosos, los misioneros procuraron alejar a los indígenas de sus celebraciones religiosas tradicionales, pues, según ellos, estaban contaminadas de supersticiones y borracheras. Así, para evitar su participación en ellas, organizaron festividades alternativas que coincidían con las fechas de las celebraciones tradicionales ${ }^{41}$. Finalmente, los misioneros establecie-

40 "Glimpses of the Work in Peru", South America. The Continent of Opportunity, Londres. VII: 3 (enero-marzo 1919), p. 31; John Ritchie, "Un llamamiento pro-indígena", El Cristiano, 92 (mayo 1919), p. 72; "An Object Lesson. Ontario Oats and a Half Feet High in Peru", Neglected Continent, 5: 9 (diciembre 1921), pp. 156-157. En el West Coast Leader, reconocido periódico británico dedicado a asuntos sudamericanos, un especialista en agricultura comentó lo siguiente respecto a la hacienda: "El señor Payne, en mi estimación, está haciendo el principio de una mejora en la agricultura de toda esta región. (...) Los métodos y productos de hoy pueden mejorarse y serán mejorados. El número limitado de clases mejores de granos y ganado, y la economía de la trilladera manual sobre los métodos de los indígenas, que se demuestran en esta hacienda, son, en mi opinión, mucho más adecuados al caso que una propaganda prolija", Cit. en "Noticias", El Heraldo, 47 (agosto 1915), p. 119. bre 1913).

${ }^{41}$ Edward Foster, "Our First Harvest Festival", South America, II: 18 (octu- 
ron un orfanato para niños indígenas abandonados que llegó a albergar a 30 huérfanos en 1921, complementando así su labor indigenista ${ }^{42}$.

La UESA también intentó establecer alguna obra entre los indígenas de la selva. En 1913, a raíz de las denuncias de Sir Roger Casement sobre la explotación de los indígenas por los caucheros en la selva peruana, la UESA envió una expedición de tres misioneros a la zona del Putumayo para comprobar in situ las atrocidades denunciadas y estudiar la posibilidad de establecer una misión. A pesar del entusiasmo que esto produjo, manifestado en las numerosas donaciones recibidas para sufragar sus gastos, la expedición no tuvo éxito y regresó a Inglaterra ${ }^{43}$. Aunque la UESA no hizo nuevos intentos por alcanzar a los indígenas de la selva, años después otras misiones reanudaron el esfuerzo. Así, en 1924, el misionero Roger Winans, de la IN, inició un trabajo social entre los aguarunas en Pomará, a las orillas del Marañón (Amazonas). Allí estableció una pequeña escuela y empezó a sistematizar la lengua aguaruna para poder alfabetizar a los indígenas en su propio idioma. Dos años después, la ACM inició sus labores en el Perú estableciendo una base misionera entre los campas de Cahuapanas, en las selvas de Pachitea (Huánuco), que llegó a contar con una escuela y adiestró a los indígenas en la agricultura y el comercio ${ }^{44}$. Así, mientras que los

42 Guillermo Millham, "La Obra de la Unión Evangélica en el Perú", Renacimiento, 118 (julio 1921), p. 106.

43 Entre 1912 y 1913 se escribieron numerosos artículos en la revista South America sobre el tema: "Putumayo atrocities", I: 5 (septiembre 1912), pp. 105-106; Stuart McNairn, "The call of the Putumayo", I: 6 (octubre 1912), p. 126; Edward Reed, "Off to the Putumayo", I: 9 (enero 1913), pp. 208-209; E. T. Glenny, "The Putumayo Expedition", II: 16 (agosto 1913), p. 85. Para oponerse a este esfuerzo, el Vaticano anunció el envío de misioneros católicos al Putumayo. "La Santa Sede y los sucesos del Putumayo", La Unión, 13 (13-enero-1913), p. 1.

44 "La conquista de las tierras bajas del Amazonas", Renacimiento, 213 (junio 1929), p. 84; "La situación presente de los indins de la selva", Renacimiento, 215 (agosto 1929), p. 117; Federico Kowalchuk, La historia y el mensaje de la Alianza Cristiana y Misionera (mímeo), Lima, s. f., p. 42-43. Ver también Kenneth Grubb, The Lowland Indians of Amazonia: A survey of the Location and Religious Condition of the Indians of Colombia, Venezuela, the Guianas, Ecuador, Peru, Brazil and Bolivia, Londres, World Dominion Press, 1927. 


\section{JUAN FONSECA}

indigenistas se dedicaban preferentemente a defender los derechos de los indígenas de la sierra, los protestantes iniciaron esfuerzos importantes entre las comunidades nativas de la selva. En décadas posteriores esta labor se extenderá notablemente, a tal punto que una buena proporción de los indígenas selváticos en la actualidad son protestantes. En este caso, el aislamiento en el que estaban favoreció la plena aceptación por parte de las tribus selváticas del mensaje protestante y los cambios que traía consigo.

Otra forma de acercamiento protestante a la realidad indígena fue a través de la literatura. Los misioneros apoyaron la labor difusora del quechua iniciada por algunos indigenistas y procuraron traducir algunos textos bíblicos a los idiomas nativos. En 1915, Julián Palacios, profesor de la Escuela Normal y miembro de la IME, estableció una academia para la enseñanza del quechua y el aimara para los estudiantes normalistas. Ese esfuerzo fue apoyado fervorosamente por algunos metodistas peruanos con expresiones como ésta:

"¿No sería más cuerdo, en vez de afanarnos por traer gente de fuera, que una vez establecida, olvidando los beneficios obtenidos en el país que nos menosprecia, fomentar el despertamiento, ayudar el resurgimiento de nuestra raza aborigen, cuyas faltas $y$ vicios actuales son en realidad insignificantes al lado de las virtudes de laboriosidad, resistencia para el trabajo, sobriedad, amor a la patria, piedad religiosa, que se desarrolla en ella cuando se la educa debidamente?"45.

Además, durante algunos periodos, revistas protestantes como El Heraldo tuvieron secciones escritas en quechua, en especial de himnos religiosos, para promover el conocimiento de ese idioma. El misionero Webster Smith (UESA), por su dominio de esa lengua, fue el promotor de ello y de una traducción del evangelio de san Mateo al quechua de Huánuco en 1915, con el fin de comunicar

45 "Enseñanza del quechua", El Mensajero, 2 (enero 1915), p. 7. También ver "La Sociedad Misionera Nacional y su obra", El Mensajero, 21 (septiembre 1916) p. 6 . 
mejor su mensaje a los indígenas. Años después, otro misionero afirmaba que "el keshua debe expresar a su modo el alma del Nuevo Testamento" 46 . Desde allí, el conocimiento de los idiomas nativos fue posteriormente considerado un elemento valioso para los fines evangelizadores de otros misioneros ${ }^{47}$.

\section{A MODO DE CONCLUSIÓN}

La relación de los protestantes con el indigenismo y su labor con los indígenas fue otro espacio en el cual compartieron su interés en promover formas modernas de pensamiento y de relaciones sociales desde sus particulares planteamientos religiosos. En algunos aspectos, sus planteamientos estuvieron relacionados con los de los indigenistas; no obstante, desarrollaron una labor que dependía fundamentalmente de sus ideas religiosas y su trasfondo cultural.

Las acciones a favor de los indígenas fueron el aspecto práctico de la religión protestante. Aunque el mundo andino, con todas sus complejidades, no fue comprendido en toda su plenitud por los misioneros, las acciones mostraron su evidente interés por hacerlo. Sus ideas y prejuicios sobre el mundo andino, por lo general, repiten los argumentos positivistas y mantienen una visión etnocentrista. No obstante, acorde con la practicidad y eticidad protestante, para los misioneros lo más importante era desarrollar acciones que contribuyeran a mejorar el nivel de vida de la población andina. En ese proceso, la confrontación con la realidad obligó a replantear algunos de los planteamientos protestantes sobre el Ande. Con el tiempo, la progresiva nacionalización del liderazgo protestante ha mostrado un creativo proceso de inculturación que trabajos posteriores pueden $y$ deben analizar.

46 F. Pastor, "Opinión sobre la traducción keshua del Nuevo Testamento", Renacimiento, 187 (abril 1927), p. 55.

47 Anteriormente, el misionero metodista Thomas Wood había traducido el evangelio de san Lucas para completar la obra de traducción de Clorinda Matto de Turner en Buenos Aires. Adolfo Vásquez, Op. Cit., p. 18; "Noticias de la Obra Evangélica", El Heraldo, 40 (enero 1915), p. 35; "Un trozo del evangelio según san Mateo en quechua de Huánuco", El Heraldo, 49 (octubre 1915), p. 140; H. W. Cragin, "Algunas sugestiones para la ortografía práctica de las lenguas quechua y aymará", Renacimiento, 231 (diciembre 1930), p. 140. 